\title{
Sebaceoma: um desafio diagnóstico - relato de caso
}

\author{
Sebaceoma: a diagnostic challenge - case report \\ Sebaceoma: un desafío de diagnóstico - informe de caso
}

\section{Resumo}

Objetivo: O sebaceoma é uma lesão benigna, mas pode estar associada a malignidades cutâneas e internas e assim pode não ter um bom prognóstico, como quando em associação com a Síndrome de Muir-Torre (SMT). Metodologia: Trata-se de um relato de caso clínico com a finalidade de descrever e discutir o caso apresentado. Descrição do Caso: O caso em questão, retrata um paciente do sexo feminino, 45 anos, com uma pápula de $0,3 \mathrm{~cm}$, fibroelástica e amarelada em região malar há cerca de 5 anos, sem outros sintomas associados e sem critérios dermatoscópicos específicos ao exame dermatológico. As seguintes hipóteses diagnósticas foram feitas à primeira instância: hiperplasia sebácea, cisto sebáceo ou cisto epidérmico. Foi optado pela exérese cirúrgica da lesão por incômodo estético da paciente. $\mathrm{O}$ estudo anatomopatológico mostrou a presença de blocos celulares arredondados e justapostos com diferenciação sebácea. Perifericamente, compostos por células basalóides, além de células neoplásicas poliédricas, grandes, com citoplasma indistinto e escasso, além de núcleos volumosos com pleomorfismo variando de leve a moderado, cromatina grosseiramente vesiculosa e frequentes mitoses. À imunohistoquímica, houve expressão de adipofilina nas células sebáceas, em padrão microgoticular, além de positividade difusa para a proteína p63. Assim, deu-se o diagnóstico de sebaceoma. Conclusão: Esse caso nos traz a reflexão da dificuldade de diferenciação clínica e dermatoscópica dos tumores de origem sebácea e também mostra a importância da necessidade de atenção à possibilidade de associação do sebaceoma à Síndrome de Muir-Torre, o que pode alterar o prognóstico do paciente. No caso em questão, não havia critérios clínicos específicos que nos fizessem levantar essa possibilidade diagnóstica.

Palavras-chave: Sebaceoma; Tumores de glândula sebácea; Síndrome de Muir Torre; Neoplasias cutâneas; Neoplasias de anexos e de apêndices cutâneos; Glândulas sebáceas; Herança genética.

\begin{abstract}
Objective: Sebaceomas are benign lesions but they can be associated with cutaneous and internal malignancies and, thus, may not have a good prognosis, as when associated with the Muir-Torre Syndrome (MTS). Methodology: This is a clinical case report aimed at describing and discussing the case presented. Description of the case: The case in question presents a female patient aged 45 years old, with a fibroelastic and yellowish $0.3 \mathrm{~cm}$ papule in the malar region for nearly 5 years, without any other associated symptoms or dermatoscopic criteria specific to the dermatological exam. The following diagnostic hypotheses were made at first instance: sebaceous hyperplasia, sebaceous cyst or epidermal cyst. The choice was to perform surgical exeresis of the lesion due to the aesthetic inconvenience it generated to the patient. The anatomopathological study showed presence of roundish and juxtaposed cell blocks with sebaceous differentiation; peripherally consisting of basaloid cells, in addition to polyhedral neoplastic cells, large and with indistinct and scarce cytoplasm, in addition to voluminous nuclei with mild to moderate pleomorphism, coarse vesicular chromatin and frequent mitosis. In the immunohistochemistry test, there was adipophilin expression in the sebaceous cells, with a microgoticular pattern, in addition to diffuse positivity for protein p63. Consequently, a sebaceoma diagnosis was made. Conclusion: This case made us reflect about the difficulty regarding clinical and dermatoscopic differentiation of sebaceous tumors; it also shows the importance of the need to pay attention to the possibility of an association between sebaceoma and the Muir-Torre Syndrome, which can alter the patient's prognosis. In the case in question, there were no specific clinical criteria that made us raise that diagnostic possibility.
\end{abstract}

Keywords: Sebaceoma; Sebaceous gland tumors; Muir Torre Syndrome; Skin neoplasms; Skin appendages and appendices neoplasms; Sebaceous glands; Genetic inheritance. 


\begin{abstract}
Resumen
Objetivo: El sebaceoma es una lesión benigna; sin embargo, puede estar asociado con malignidades cutáneas e internas y, por lo tanto, es posible que no tenga un buen pronóstico, como cuando se asocia con el Síndrome de MuirTorre (SMT). Metodología: Se trata de un informe de caso clínico con el fin de describir y debatir el caso presentado. Descripción del caso: El caso en cuestión describe a una paciente de 45 años de edad con una pápula fibroelástica y amarillenta de $0,3 \mathrm{~cm}$ en la región malar desde hace aproximadamente 5 años, sin otros síntomas asociados ni criterios dermatoscópicos específicos según el examen dermatológico. En primera instancia, se formularon las siguientes hipótesis de diagnóstico: hiperplasia sebácea, quiste sebáceo o quiste epidérmico. Se optó por exéresis quirúrgica de la lesión dada la incomodidad estética que generaba en la paciente. En el estudio anatomopatológico se evidenció la presencia de bloques celulares redondeados y yuxtapuestos con diferenciación sebácea; periféricamente compuestos por células basaloides, además de células neoplásicas poliédricas, grandes y con citoplasma indistinto y escaso, además de núcleos voluminosos con pleomorfismo de leve a moderado, cromatina vesicular grumosa y mitosis frecuentes. En la prueba inmunohistoquímica hubo expresión de adipofilina en las células sebáceas, con patrón microgoticular, además de positividad difusa para la proteína p63. De esta manera, se llegó al diagnóstico de sebaceoma. Conclusión: Este caso nos hizo reflexionar acerca de la dificultad en relación con la diferenciación clínica y dermatoscópica de los tumores de origen sebáceo; también demuestra lo importante y necesario que es considerar la posibilidad de una asociación entre el sebaceoma y el Síndrome de Muir-Torre, lo que puede alterar el pronóstico del paciente. En el caso en cuestión no había criterios clínicos específicos que nos hicieran considerar esa posibilidad diagnóstica.
\end{abstract}

Palabras clave: Sebaceoma; Tumores de las glándulas sebáceas; Síndrome de Muir Torre; Neoplasias cutáneas; Neoplasias de apéndices y apéndices cutáneos; Glándulas sebáceas; Herencia genética.

\title{
1. Introdução
}

A distinção entre lesões de origem sebácea pelo exame clínico e dermatoscópico representa um desafio (Tavares et al., 2012). Clinicamente há uma pápula, nódulo ou uma tumoração exofítica arredondada, amarelo-alaranjada, predominantemente solitária, mas podendo ser múltipla, em áreas seborreicas do corpo, principalmente no couro cabeludo (Flux, 2017). Dermatoscopicamente, há uma área amorfa eritêmato-amarelada, com vasos arboriformes de ramificação centrípeta, podendo haver ulcerações (Coppola et al., 2015).

Os tumores originados das glândulas sebáceas são pouco frequentes. Essas neoplasias podem ser classificadas como: hamartomas sebáceos (nevo organóide ou nevo sebáceo), tumores sebáceos benignos (adenomas sebáceos ou sebaceomas), tumores sebáceos malignos (carcinoma sebáceo) e outras neoplasias com diferenciação sebácea (basalioma e tricoblastoma com diferenciação sebácea). A diferenciação entre eles será por meio da histopatologia, de acordo com o grau de diferenciação sebácea, a citologia e os padrões arquiteturais (Böer-Auer, 2014; Flux, 2017; Iacobelli, Harvey \& Wood, 2017; Misago \& Narisawa, 2000; Monti et al., 2017; Poggi et al., 2019; Rivitti, 2018; Tavares et al., 2012; Troy \& Ackerman, 1984).

O sebaceoma é uma lesão benigna, mas a Síndrome de Muir Torre (SMT) pode ter associação com malignidades cutâneas e internas e assim pode não ter um bom prognóstico (Hare et al., 2008; Higgins, Voutsalath \& Holland, 2009; Lazar, Lyle \& Calonje, 2007; Misago et al., 2002; Rivitti, 2018).

Esse relato de caso tem como objetivo ressaltar a importância do diagnóstico do sebaceoma, como diagnóstico diferencial das lesões cutâneas benignas, o qual pode ter relação com a SMT, podendo alterar o prognóstico do paciente.

\section{Metodologia}

Trata-se de um relato de caso clínico com a finalidade de descrever e discutir o caso apresentado. O relato de caso é uma abordagem metodológica utilizada para proporcionar melhor compreensão de determinado assunto em seu contexto na prática. O princípio central do estudo de um caso é a necessidade de explorar um assunto profundamente, em seu contexto natural, buscando explica-lo e descrevê-lo. As principais etapas deste tipo de estudo envolvem: definir e selecionar o caso; coletar, analisar e interpretar os dados e relatar os achados (Crowe et al., 2011). Este relato de caso foi aprovado pelo Comitê de Ética em Pesquisa com Seres Humanos da Universidade do Oeste Paulista - Unoeste (CAAE nº 52755421.4.0000.5515) e a 
paciente assinou o Termo de consentimento livre e esclarecido concordando com a publicação do caso.

\section{Resultados e Discussão}

Paciente do sexo feminino, 45 anos, apresentava lesão em região malar esquerda há pelo menos 5 anos, sem sintomas associados. Relatou que já havia tentado retirar a lesão algumas vezes por meio de limpeza de pele, sem sucesso. Referia não ter notado o crescimento da lesão desde seu surgimento. Ao exame físico dermatológico, observou-se pápula normocrômica ligeiramente amarelada de $0,3 \mathrm{~cm}$, de consistência fibroelástica, com bordas sutis com relação à transição para a pele sã, além de telangectasias centrípetas centrais (Figura 1).

Aventou-se então a possibilidade de hiperplasia sebácea, cisto sebáceo ou cisto epidérmico. Foi realizada exérese da lesão apenas por questões estéticas e desejo da paciente.

Figura 1 - Lesão clínica caracterizada por pápula bem delimitada amarelada, medindo 0,3cm de diâmetro (seta).

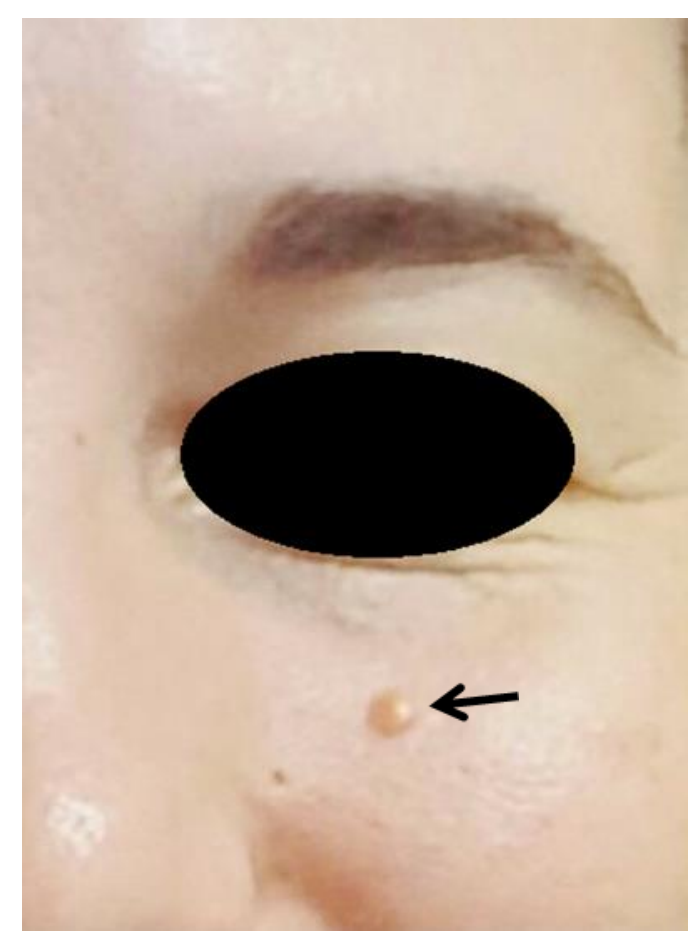

Fonte: Acervo próprio.

O material foi enviado para exame anatomopatológico e à microscopia, observou-se segmento de pele em cuja derme estava alojada a uma neoplasia epitelial anexial, nodular, circunscrita, não capsulada, medindo cerca de 3,0 mm de diâmetro (Figuras 2 e 3). A neoplasia consistia em blocos celulares arredondados e justapostos, vários deles apresentando evidente diferenciação sebácea. Na periferia da lesão, os blocos justapostos eram compostos em grande parte de células basalóides; nas áreas restantes as células neoplásicas eram poliédricas, grandes, com citoplasma escasso e indistinto, além de núcleos volumosos com pleomorfismo de leve a moderado, dotados de cromatina grosseiramente vesiculosa e apresentando frequentes mitoses (Figura 3). As margens cirúrgicas laterais e profundas estavam livres de neoplasia.

O estudo imunohistoquímico revelou expressão de adipofilina nas células sebáceas, em padrão microgoticular, além de positividade difusa para a proteína p63 (Figura 4). Com os achados histológicos e imunohistoquímicos, o diagnóstico foi de sebaceoma. 
Research, Society and Development, v. 11, n. 1, e25511124376, 2022

(CC BY 4.0) | ISSN 2525-3409 | DOI: http://dx.doi.org/10.33448/rsd-v11i1.24376

Figura 2 - Fotomicroscopia da neoplasia cutânea mostrando blocos celulares arredondados e justapostos, e áreas com diferenciação sebácea (Hematoxilina-eosina, aumento de 40x).

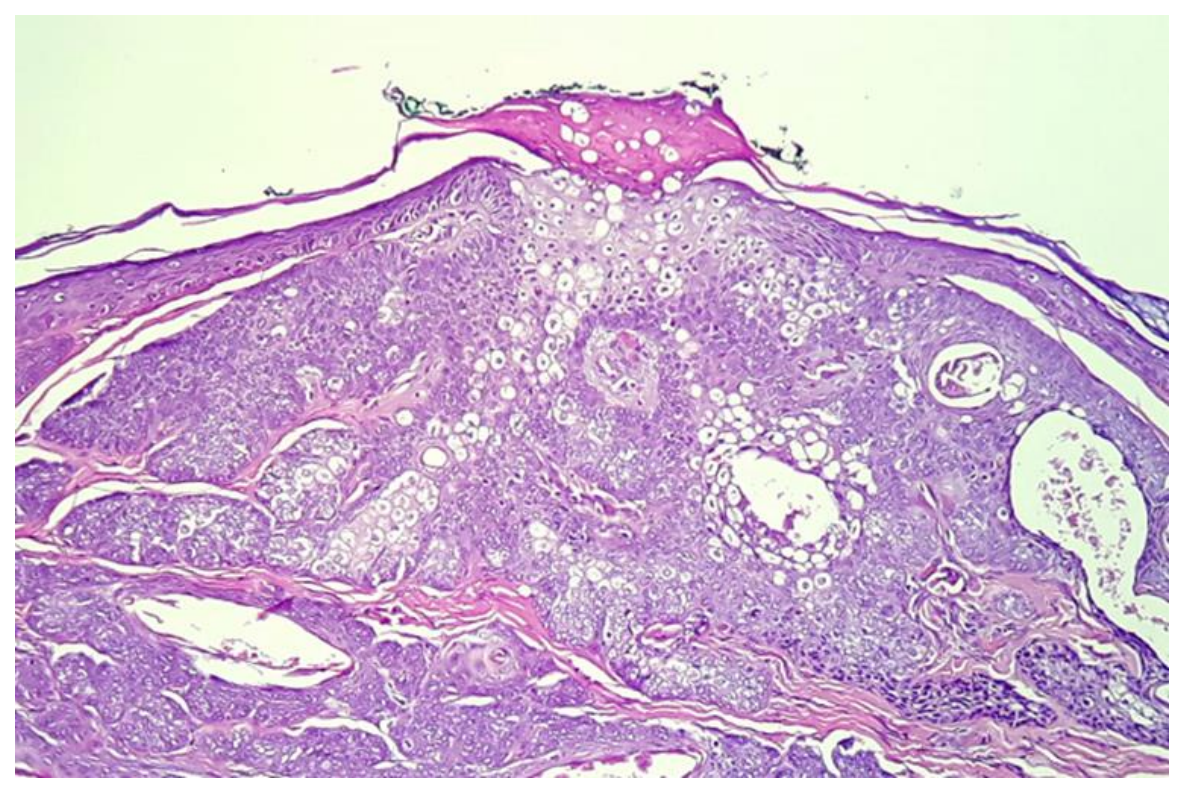

Fonte: Acervo próprio.

Figura 3 - Fotomicroscopia da neoplasia cutânea mostrando área mais bem diferenciada à esquerda, com células de citoplasma vesiculoso, semelhantes à glândula sebácea e área menos diferenciada à direita constituída de blocos de células com núcleos vesiculosos e nucléolos evidentes, circundados por células basalóides (Hematoxilina-eosina, aumento de 400x).

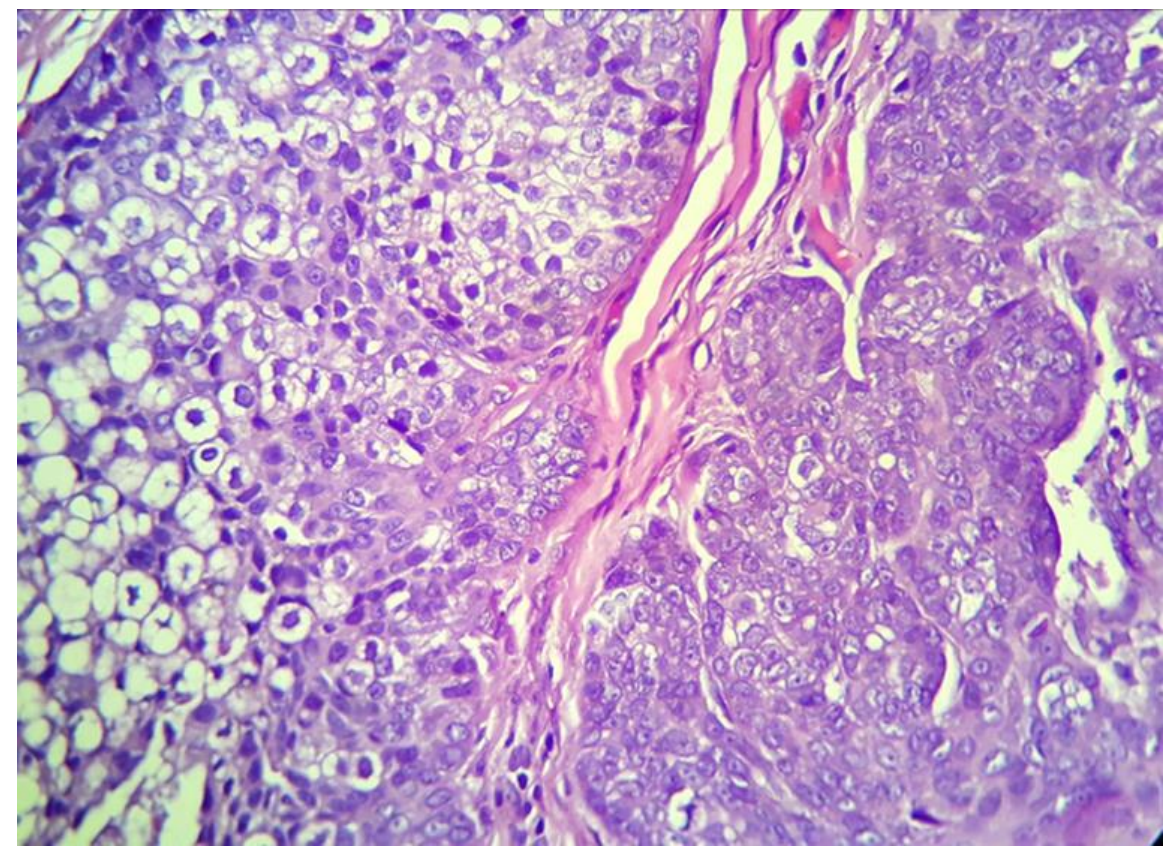

Fonte: Acervo próprio. 
Figura 4 - Imunomarcação para adipofilina nas células sebáceas da neoplasia. Imunomarcação difusa para proteína p63 nas células neoplásicas.

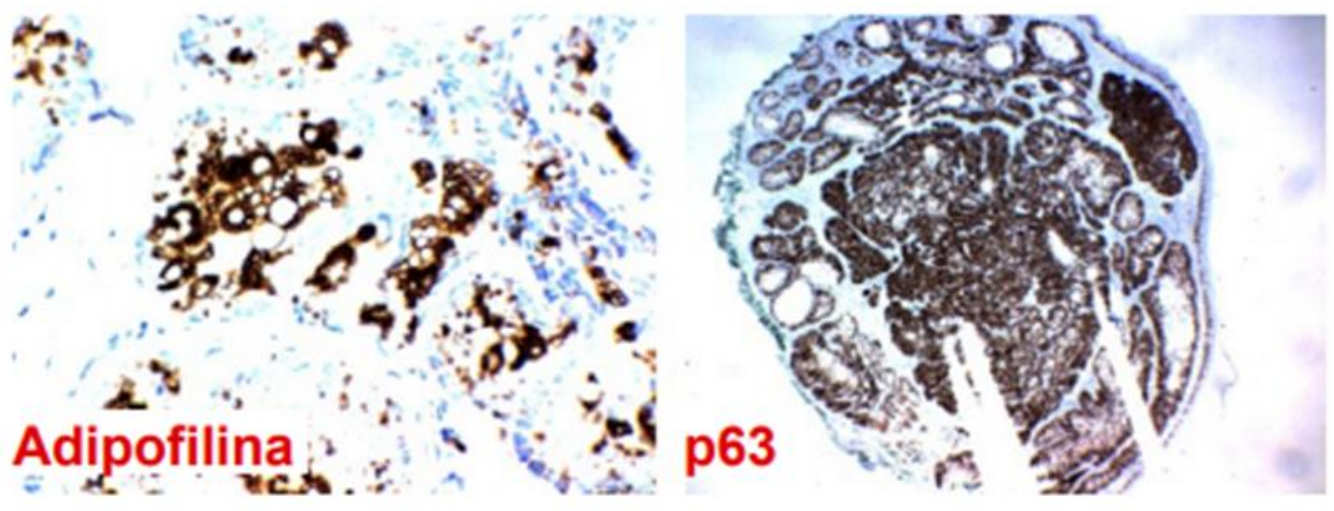

Fonte: Acervo próprio.

Foi realizada a exérese completa da lesão, sem necessidade de nova intervenção após avaliação anatomopatológica.

A paciente não apresentava critérios diagnósticos para SMT, negava antecedentes pessoais e familiares para neoplasias malignas, tanto viscerais, quanto cutâneas.

A paciente mantém-se em seguimento periódico com dermatologista e, até o momento, não houve surgimento de novas lesões e permanece sem critérios para diagnóstico de SMT.

O diagnóstico das neoplasias sebáceas é de extrema importância em decorrência dos diferentes tipos de tratamento e prognóstico de acordo com a sua classificação, mas também devido à possível associação com a Síndrome de Muir-Torre (SMT) (Hare et al., 2008; Higgins, Voutsalath \& Holland, 2009; 16. John \& Schwartz, 2016; Lazar et al., 2007; Misago et al., 2002).

Clinicamente, as neoplasias sebáceas cutâneas têm predileção pelas regiões de cabeça e pescoço em adultos, sendo a maioria solitária e esporádica (Ferreira et al., 2020).

Geneticamente, as neoplasias sebáceas cutâneas apresentam alta frequência de instabilidade microssatélites (instabilidade genômica). Em um indivíduo saudável, quando há incompatibilidade ou erro de base genética durante a replicação o DNA, faz-se o reparo por meio de proteínas de reparo de incompatibilidade de DNA (MMR, codificadas por exemplo por MSH2, MSH6 e MLH1). Quando ocorre deficiência de proteínas MMR no genoma de um indivíduo, ocorrem mutações acumuladas em microssatélites. A imunoistoquímica é um método de triagem patológica importante para determinar se o genoma de um tumor apresenta estabilidade ou instabilidade microssatélite, o que auxiliará no diagnóstico da SMT (Torre et al., 2019).

O sebaceoma é mais frequente em mulheres, sem predileção por raça, afeta normalmente adultos a partir da quinta década de vida, principalmente na oitava década de vida (Rivitti, 2018; Tavares et al., 2012). Clinicamente, trata-se de uma pápula, placa, nódulo ou mais raramente um tumor, geralmente com 2-3 mm até $1 \mathrm{~cm}$. É frequentemente lobulado, consistente, liso, amarelo-alaranjado-avermelhado, predominantemente único (raramente múltiplo), localizado na cabeça e pescoço, em áreas seborreicas do corpo, como face e, principalmente, couro cabeludo (Poggi et al., 2019; Rivitti, 2018; Tavares et al., 2012). Dermatoscopicamente, pode ser visualizada uma área amorfa eritemato-amarelada (importante achado para natureza sebácea da lesão) com ou sem ulcerações, com vasos arboriformes de ramificação centrípeta (Tavares et al., 2012). Dessa forma, o sebaceoma pode simular clínica e dermatoscopicamente diversas outras lesões cutâneas, necessitando então do exame histopatológico para seu diagnóstico definitivo (Flux, 2017; Monti et al., 2017; Troy \& Ackerman, 1984). 
A paciente do caso em questão era ligeiramente mais nova do que a maioria dos casos epidemiologicamente. Mas, apresentava lesão clínica muito semelhante às descrições encontradas na literatura, inclusive ao exame dermatoscópico. Entretanto, devido à semelhança com outras lesões cutâneas e à raridade desse tumor, o diagnóstico definitivo dar-se-á a partir do exame histopatológico.

Histologicamente, no sebaceoma, vê-se um tumor sebáceo lobulado (podendo ser uni ou multilobular) da derme com frequente conexão epidérmica. Os nódulos tumorais são frequentemente desorganizados, com distribuição aleatória de sebócitos maduros em seu interior (difusamente isoladas por todo o tumor ou em pequenos grupos), com mais de $50 \%$ de células basalóides. As estruturas lobulares são menos definidas e predominam células epiteliais sem diferenciação sebácea evidente, embora em meio às células possam ser vistas células vacuolizadas semelhantes às células sebáceas. Geralmente não há pleomorfismos celulares ou necrose tumoral. As mitoses podem estar presentes, mas as formas atípicas não são vistas. Os ductos e os cistos são incomuns. Pode ser visto também estroma de tecido conjuntivo distinto. Em alguns casos, há sobreposição de características com adenoma sebáceo, devido à possibilidade de coexistência desses dois tipos de lesão em um mesmo tumor (Brinster et al., 2012; Bourlond et al., 2016; Ferreira et al., 2020; Tavares et al., 2012).

$\mathrm{Na}$ imunoistoquímica, geralmente há expressão de citoqueratinas de alto peso molecular p63 e p40), sendo comumente positivo para CK7 e negativo para CK20 e BerEP4. A diferenciação sebácea pode ser realizada pelo antígeno da membrana epitelial (EMA) ou pela coloração de adipofilina nas células sebáceas maduras (Ferreira et al., 2020).

Nos adenomas sebáceos, há lóbulos sebáceos com tamanhos variados e não completamente diferenciados. Perifericamente, há células basalóides; centralmente, há sebócitos com típica vacuolização; não há anaplasia celular (Brinster et al., 2012; Bourlond et al., 2016).

No caso em questão, a peça histológica apresentava blocos celulares com diferenciação sebácea com predomínio de células basalóides perifericamente circundando células vacuolizadas. Diferentemente do que é descrito na literatura, a qual diz que geralmente não há pleomorfismo celular, no caso havia um pleomorfismo variando de leve a moderado. Além disso, os marcadores imunoistoquímicos auxiliaram no diagnóstico. A adipofilina é um marcador de linhagem sebocítica. O p63 positivo indica a presença de células com alto poder proliferativo e, portanto relaciona-se a células neoplásicas. Quanto maior o grau de anaplasia e menor o grau de diferenciação, maior será a expressão da p63 e mais difusa será a sua distribuição.

A excisão cirúrgica do sebaceoma é curativa com pouca probabilidade de recorrência, portanto seu prognóstico é bom, dada a origem benigna do tumor. Porém, em decorrência da sua possível associação com a SMT, deve-se atentar para a possibilidade de outras malignidades cutâneas e internas (Hare et al., 2008; Higgins et al., 2009; Lazar et al., 2007; Misago et al., 2002).

A SMT é uma condição genética rara e potencialmente agressiva que predispõe indivíduos a tumores de pele e malignidades viscerais, sendo mais frequente em homens. Pode ser esporádica menos frequentemente, em transplantados e imunossuprimidos. Pode ser classificada em:

a) SMT I: maioria (65\%), autossômica dominante, com alta penetrância e expressão variável. Caracterizada por tumores de início precoce, porém a expressão e o desenvolvimento dos tumores são variáveis (Torre et al., 2019). Ocorrem mutações nos genes de reparação de bases mal pareadas (MMR) responsáveis pela deteç̧ão e reparo de erros durante a replicação de DNA, ocorrendo perda da expressão de MSH2 (principalmente - 90\%), MLH1 e MSH6 (mais raramente). Ocorre um acúmulo de erros de replicação e aumento da instabilidade microsatélite (MSI), causando um mau funcionamento dos genes de supressão tumoral, gerando a carcinogênese tecidual;

b) SMT II: 35\% dos pacientes, autossômica recessiva, sem instabilidade de microssatélite. Ocorre inativação bialélica de MYH1, uma base gene de reparo celular. Apresenta penetrância moderada a baixa. Os tumores têm início mais posteriormente e pode ter associação com polipose intestinal. 
A SMT é caracterizada pela associação entre múltiplas neoplasias sebáceas e malignidades internas com comportamento menos agressivo comparativamente às fora do contexto da síndrome. Das neoplasias cutâneas, as mais comuns são os adenomas sebáceos (68\%), sendo esses um marcador mais específico para a síndrome (Finan \& Connolly, 1984). Com menor frequência podem ser encontrados também: sebaceoma, carcinoma sebáceo, sebo-queratoacantoma e carcinomas com diferenciação sebácea. Das malignidades internas, a mais frequente é o carcinoma colorretal não polipóide associado à Síndrome Lynch, ou Síndrome de Carcinoma colorretal não polipose hereditário (HNPCC). A Síndrome acomete 9,2\% dos indivíduos e $28 \%$ das famílias com HNPCC. Pode estar também associada às neoplasias de mama e do trato urinário com menor frequência.

Primeiramente surgem as malignidades internas em 56\% dos casos, as neoplasias cutâneas em 22\%, mas podem surgir simultaneamente em 6\% e podem não ter relação temporal em 16\% (Hare et al., 2008; Higgins et al., 2009; John \& Schwartz, 2016; Lazar et al., 2007; Misago et al., 2002).

Os critérios diagnósticos para SMT estão descritos no Quadro 1:

Quadro 1 - Critérios diagnósticos para Síndrome de Muir-Torre.

\begin{tabular}{|l|l|}
\hline Grupo A & Adenoma sebáceo \\
& $\begin{array}{l}\text { Epitelioma sebáceo } \\
\text { Carcinoma sebáceo } \\
\text { Seboqueratoacantoma } \\
\text { Imunohistoquímica do tumor demonstrando negatividade dos genes MLH1 e MSH6 ou MSH2/MLH1 e MSH6 } \\
\text { Instabilidade microssatélite nas células tumorais }\end{array}$ \\
\hline Grupo B & $\begin{array}{l}\text { Malignidade visceral } \\
\text { Tumor colorretal com instabilidade microssatélite }\end{array}$ \\
\hline Grupo C & $\begin{array}{l}\text { Múltiplos queratoacantomas } \\
\text { Múltiplas malignidades viscerais } \\
\text { História familiar de SMT }\end{array}$ \\
\hline $\begin{array}{l}\text { Resultados de teste } \\
\text { genético }\end{array}$ & $\begin{array}{l}\text { 1. Positivo: detecção de mutação patogênica } \\
\text { 2. Negativo: não identificado mutação, o que não exclui uma mutação não testada, considerando fortemente } \\
\text { o histórico pessoal e familiar de malignidade. } \\
\text { 3. Inconclusivo: variante de significado incerto. }\end{array}$ \\
\hline
\end{tabular}

Fonte: Rivitti (2018).

Sendo necessários pelo menos uma característica do grupo A e B ou as três características do grupo C. Indica-se a pesquisa genética do paciente quando detectada a presença de neoplasia sebácea em associação à história familiar ou pessoal de malignidade, de acordo com análise histológica do tumor, além do exame clínico e de imagem se necessário.

\section{Conclusão}

$\mathrm{O}$ relato retrata um caso que contrasta com a literatura epidemiologicamente, sendo a paciente ligeiramente mais jovem do que a maioria dos casos descritos, tendo o tumor surgido por volta dos seus 40 anos de vida. Além disso, clínica e dermatoscopicamente não foi possível afirmar o diagnóstico de sebaceoma à primeira instância, tendo sido feitas as hipóteses de hiperplasia sebácea, cisto sebáceo ou cisto epidérmico, que são diagnósticos diferenciais.

Demonstramos assim, que a diferenciação clínica e dermatoscópica dos tumores de origem sebácea, benignos e malignos, nem sempre é possível.

Ressaltamos a importância de seu diagnóstico histopatológico, não só pela dificuldade de definição clínica, mas também pela possibilidade do sebaceoma estar associado à SMT, o que impacta no prognóstico dos pacientes. Sugerimos trabalhos futuros que abordem como melhorar a acurácia diagnóstica desse tipo de tumor. 


\section{Referências}

Brinster, N. K., Liu, V., Diwan, H., \& Mckee, P. H. (2012). Dermatopatologia. Elsevier.

Böer-Auer, A. (2014). Differential diagnostics of sebaceous tumors. Pathologe, 35(5), 443-455. https://doi.org/10.1007/s00292-014-1934-y.

Bourlond, F., Velter, C., \& Cribier, B. (2016). Clinicopathological study of 47 cases of sebaceoma. Annales de Dermatologie et de Vénéréologie, 143(12), 814-824. https://doi.org/10.1016/j.annder.2016.06.013.

Coppola, R., Carbotti, M., Zanframundo, S., Rinati, M. V., Graziano, A., \& Panasiti, V. (2015). Use of dermoscopy in the diagnosis of sebaceoma. Journal of the American Academy of Dermatology, 72(6), e143-e145. https://doi.org/10.1016/j.jaad.2014.12.004.

Crowe, S., Cresswell, K., Robertson, A., Huby, G., Avery, A., \& Sheikh, A. (2011). The case study approach. BMC Medical Research Methodology, 11(100). https://doi.org/10.1186/1471-2288-11-100.

Ferreira, I., Wiedemeyer, K., Demetter, P., Adams, D. J., Arends, M. J., \& Brenn, T. Update on the pathology, genetics and somatic landscape of sebaceous tumours. (2020). Histopathology, 76, 640-649. https://doi.org/10.1111/his.14044.

Finan, M. C., \& Connolly, S. M. (1984). Sebaceous gland tumors and systemic disease: a clinicopathologic analysis. Medicine (Baltimore), 63(4), 232-242. https://doi.org/10.1097/00005792-198407000-00005.

Flux, K. (2017). Sebaceous Neoplasms. Surgical Pathology Clinics, 10(2), 367-382. https://doi.org/10.1016/j.path.2017.01.009.

Hare, H. H., Mahendraker, N., Sarwate, S., \& Tangella, K. (2008). Muir-Torre syndrome: a rare but important disorder. Cutis, 82(4), $252-256$.

Higgins, H. J., Voutsalath, M., \& Holland, J. M. (2009). Muir-torre syndrome: a case report. The Journal of Clinical and Aesthetic Dermatology, 2 (8), 30-32.

Iacobelli, J., Harvey, N. T., \& Wood, B. A. (2017). Sebaceous lesions of the skin. Pathology, 49(7), 688-697. https://doi.org/10.1016/j.pathol.2017.08.012.

John, A. M., \& Schwartz, R. A. (2016). Muir-Torre syndrome (MTS): An update and approach to diagnosis and management. Journal of the American Academy of Dermatology, 74(3), 558-566. https://doi.org/10.1016/j.jaad.2015.09.074.

Lazar, A. J., Lyle, S., \& Calonje, E. (2007). Sebaceous neoplasia and Torre-Muir syndrome. Current Diagnostic Pathology, 13(4), 301319. https://doi.org/10.1016/j.cdip.2007.05.001.

Misago, N., Mihara, I., Ansai, S., \& Narisawa, Y. (2002). Sebaceoma and related neoplasms with sebaceous differentiation: a clinicopathologic study of 30 cases. The American Journal of Dermatopathology, 24(4), 294-304. https://doi.org/10.1097/00000372-200208000-00002.

Misago, N., \& Narisawa, Y. (2000). Sebaceous neoplasms in Muir-Torre syndrome. The American Journal of Dermatopathology, 22(2), 155-161. https://doi.org/10.1097/00000372-200004000-00012.

Monti, F. C., Bonetto, V. N., Valente, E., Kurpis, M., \& Ruiz Lascano, A. (2017). Sebaceomas: report of two cases. Revista Argentina de Dermatologia, $98(2)$.

Poggi, B. C., Melo, D. F., Costa, J. M., \& Sousa, M. A. J. (2019). Sebaceoma on the scalp simulating a malignant pigmented neoplasia. Anais Brasileiros de Dermatologia, 94, 590-593. https://doi.org/10.1016/j.abd.2019.09.007.

Rivitti, E. A. (2018). Dermatologia de Sampaio e Rivitti. Artes Médicas.

Tavares, E., Alves, R., Viana, I., \& Vale, E. (2012). Tumores sebáceos-revisão anátomo-clínica de três tipos histológicos. Medicina Cutánea Ibero-LatinoAmericana, 40(3), 76-85.

Torre, K., Ricketts, J., \& Dadras, S. S. (2019). Muir-Torre Syndrome: a case report in a woman without personal cancer history. The American Journal of Dermatopathology, 41(1), 55-59. https://doi.org/10.1097/DAD.0000000000001210.

Troy, J. L., \& Ackerman, A. B. (1984). Sebaceoma. A distinctive benign neoplasm of adnexal epithelium differentiating toward sebaceous cells. The American Journal of Dermatopathology, 6(1), 7-13. 